\title{
Design, Development and Performance Evaluation of Manure Spreader- A Review
}

\author{
C. Naveen Kumar* and N. L. Kalyan Chakravarthi \\ Department of Farm Machinery and Power Engineering, \\ College of Technology and Engineering, Udaipur-313001, Rajasthan, India
}

*Corresponding author

\section{A B S T R A C T}

\section{Keywords}

Fertilizer, Spreader, Application rate, Coefficient of uniformity

\section{Article Info}

Accepted:

24August 2019

Available Online:

10 September 2019
Application of fertilizers plays a vital role in crop production system. The basic performance parameter for a fertilizer distributor was uniformity of distribution over a wide range of conditions. In India traditionally manure was distributed with the help of fork and other mechanical device which was very tedious and slow process. The study of the previous work done on fertilizer applicators shows that manually operated, animal drawn and tractor drawn spreader has been developed in India to achieve uniformity in application with minimum time and drudgery of labor. Some of those studies have been reviewed in this study.

\section{Introduction}

Agriculture remains the principal source of livelihood for majority of the population in India. The increased use of synthetic fertilizers and chemical pesticides in agriculture started in India since 1960s as part of the Green Revolution. Over the past five decades synthetic fertilizers' consumption has drastically increased several folds and India is now one of the leading producers of agrochemicals in the world. Soil is an essential nutrient source for the plant, crop plants draw nutrients from the soil and therefore, application of fertilizer is very important to maintain the productivity of soil (Krishanchandra, 2005). We witnessed a change from organic to inorganic agriculture and now, thinking a move towards organic again (Sathyanarayana et al., 2002).

Nutrient supply in crop system should be economically viable, environmental friendly and socially acceptable without affecting the gross plant production (Krishanchandra, 2005). Meanwhile, Organic manure is considered as eco-friendly bio-fertilizers for highly polluted modern era. When comes to application method of dry fertilizer, broadcasting and mixing into the soil after 
plowing is popular in Indian farms. Use of manpower for application of organic materials is uneconomical due to high labor cost. Thus, it attracted wide attention in various parts of world (Kunal et al., 2018). In modern agriculture, tractor has become integral part of mechanized agriculture. In this context, in India various types of fertilizers spreaders have been developed to achieve uniformity in application rate and to reduce drudgery meanwhile to increase agriculture production (Suthakar et al., 2008).

\section{Design Parameters}

The basic performance parameter for a fertilizer distributor is uniformity of distribution over a wide range of conditions. The uniformity of spreader is determined primarily by the performance of the metering devices. The metering device should have a positive dispensing action with fertilizers covering a range of drill abilities. It is desirable that the discharge rate be proportional to the forward speed of the implement so the application rate per hectare will be independent of speed. The design should be such that there are no appreciable cyclic variations in discharge rate. The rate should be adjustable in small increments and should have a definite relation to a suitable reference scale provided on the unit (Kepner et al., 1987).

\section{Metering Devices}

Many different types of metering devices for fertilizers have been developed in recent years in attempting to obtain a consistent and uniform metering action under the wide variety of conditions encountered in distributing fertilizers. Some of the principles employed in present day distributors are described in the following paragraphs.

Hopper with centrifugal spreader disk consists of hopper, which is used to keep the Manure.
It also accommodates the flow metering mechanism. The bottom corner side of hopper contains hole and adjustor. The manure may come out from the hole and the adjustor is used to adjust the hole. The rate of flow of manure may controlled by the adjustor. In a spreader disk types the rotating member generally driven by ground wheel. The drive gear is fastened at the center of the horizontal shaft between the wheels. The driven is connected at the one end of the vertical column. The spreader disk is placed at the other end of the vertical column as shown in Fig. 1. When the forward movement of the machine occurs, the drive gear rotate along with the wheel so by that the driven gears also rotates (Jayamurthy et al., 2018).

In similar fashion Vignesh et al., (2018) also developed the spreader where they have given power by two stroke engine shown in Fig 2. Due to centrifugal action of the spreader disk, the manure will spread around the field.

Chain conveyor with centrifugal wheel, Conveyor is made to carry manure in forward direction with maximum 100 RPM, for movement of conveyor tractor P.T.O. taken for rotation and by ratchet mechanism. Centrifugal wheel was used to give direction to manure towards the rotating plate, the centrifugal wheel also consist of crusher which was used to crush over size manure. It takes P.T.O. rotation and with chain drive it rotates with maximum 135 RPM (Kunal et al., 2018). Material used is Wooden Ply, Big Chain, M.S sheet, Ratchet \& Pawl.

Chain conveyor with feeder plate, (Suthakar et al., 2008) developed a tractor operated manure spreader where, a chain conveyor was used to carry the manure towards the spreader from the front end of the tub with help of feeder plate. The 16 feeder plates $1000 \times 40 \times 6 \mathrm{~mm}$ were welded to the endless chain with an interval distance of $450 \mathrm{~mm}$. Also, two 
inverted "L" angles $1000 \times 40 \times 40 \times 6 \mathrm{~mm}$ were provided between the feeder plates to remove the manure completely from the tub. The forward movement of the chain was achieved through the drive shaft, which was mounted at the front side of the manure tub. The driven shaft was mounted at the rear side of the manure tub. The chain was connected to the drive and driven shaft in such a way that it ran longitudinally over the manure tub.

In similar fashion Sapkale et al., (2010) have developed tractor operated manure spreader where an endless conveyor was provided at the bottom of the trailer for conveying the manure towards the rear end. For shearing off the manure and its distribution, swinging hammer type beaters were provided at rear end.

Spiral auger, Singh and Singh (2014) have developed animal drawn FYM spreader where, a manure spreading auger made of mild steel spiral discs of $2 \mathrm{~mm}$ thickness was provided below the manure box. The diameter of disc is $200 \mathrm{~mm}$. the discs are welded on MS pipe of $48 \mathrm{~mm}$ in such a way that the discs deliver manure directly to the ground. At both ends of the pipe bearings have been provided for rotation of auger. It is used to crush the lumps and spreading the manure. Chain and sprocket arrangement have been provided for rotating auger.

Stationary opening metering devices are common on drop type as well spreading type applicators. The rate is controlled by adjusting the size of the openings. A rotating spreader or agitator after openings will spread the manure which will come in contact with them. Naveenkumar et al., (2017) have developed a tractor operated FYM spreader where they have employed a adjustable frame opening shown in fig. to control the flow of farmyard manure. They have operated manure spreader by lifting tractor trolley at different slope in order to make flow of manure from front side of trolley to rear side where rotating spreader unit is given. In order to control huge or mass flow of manure to spreader unit they have provided adjustable frame. It can be lift up and down according to the application rate.

Similarly, Reddy et al., (2013) have developed a animal drawn manure spreader. Sliding plate is mainly used for adjustment of opening area in the manure box. Sliding plate is made from MS sheet and has on the bottom of platform below the agitator to control the manure delivery rate two handles were provided to the sliding plate, which helps the push or pull (forward and backward direction) the sliding plate inside the manure box. Thus by increasing or decreasing the opening width, the manure delivery rate is controlled. The sliding plate controls the opening for dropping the manure. The agitator assembly is fixed below the manure box for agitating the manure during working position. A manure spreading agitator is fixed at middle portion of main frame of rectangular chassis. The main function of agitator is to agitate the manure from manure box.

\section{Factors affecting discharge rate}

Present day metering devices have a positive action in dispensing part of flow but also depend partly upon gravity. Stationary opening arrangements depend largely upon gravity. Auger feeds, conveyor feed units are positive displacement devices. Discharge rates from metering devices that are not positive acting are materially affected by the type and condition of the fertilizer and by operating conditions, the extent of the effects being related to the degree of dependence upon gravity flow. One of the important factors affecting discharge rates is the drillability of fertilizer. Drillability or ease of flowing is affected by such factors as the hygroscopicity of the fertilizer, relative humidity at which it is 
stored, the size and shape of particles, presence of lumps, the bulk density and the compaction characteristics of the material (Kepner et al., 1987).

Mehring and Comings, 1930 found a definite relation between the kinetic angle of repose and the discharge rate, they concluded that the drillability of a fertilizer is inversely proportional to the angle of repose and that fertilizers with angles of repose greater than about $55^{\circ}$ cannot be metered satisfactorily with the most type of equipment.

Singh and Singh, 2014 concluded that the farmyard manure is heterogeneous material and moisture content of its changes with the depth of the storage pit. Hence angle of friction is more important for sliding the manure over a sheet as compared to angle of repose.

They also observed the variation of manure deliver rate at different levels of manure filled in the manure box. Meanwhile it is also evident by the research of Malgeryd and Wetterberg, 1996 the bulk density of solid manure affects spreading properties such as the flow of manure and the working width.

\section{Factors affecting application rate}

Generally application rate of fertilizer spreader vary with the size of opening and forward speed. Some of such research have discussed in below paragraphs.

The research of Patil and Munde, 2017 showed that the application rate of manure during manure spreader operation varies from 2.46 to $10.06 \mathrm{t} / \mathrm{ha}$ for different opening areas of cover from $0.04 \mathrm{~m}^{2}$ to $0.16 \mathrm{~m}^{2}$, respectively. The developed manure spreader cum cart has desired manure application rate of 9-10 t/ha for $0.16 \mathrm{~m}^{2}$ opining area of cover at the operational speed of $2.63 \mathrm{~km} / \mathrm{hr}$. The increase in manure delivery rate with increase in opening area of delivery slot was due to availability of more area, allowing increased quantity of manure to pass through.

The similar result was observed by the Jain and Lawrence, 2015. The manure delivery rate varied with variation in size of opening and ranged between 0.38 to $0.83 \mathrm{~kg}$ per second with the increase in opening area.

When it comes to the forward speed of the machine over application rate Suthakar et al., (2008) observed that the application rate of the manure was significantly decreased when increasing the forward speed. The reason was that when the forward speed was increased, application of manure over the field must be reduced.

Meanwhile chain conveyor speed was also influenced the application rate but researcher found no significant effect of drum speed in application rate. The desired application rate of manure (12.20 t/ha) was observed at the forward speed of $2.31 \mathrm{~km} / \mathrm{h}$ and the chain conveyor speed of $1.51 \mathrm{~m} / \mathrm{min}$ with the effective width of $1.20 \mathrm{~m}$ and saving in time of 50-60 per cent when compared to the conventional method.

Similar results were observed by Thakur et al., (2015) according to them increase in engine rpm and forward speed will increase field capacity but it will decrease application rate. The investigation of Shen et al., (2011) to know the causes for differences in compost application rate in a field using two types of manure spreaders and clarifying it by measuring the travel tracks of the manure spreaders using a RTK-GPS system showed the differences in compost application rate are due to the changes in travel speeds and track distances. 
Table.1 Application rate of manure for different combinations

\begin{tabular}{|c|c|c|c|c|}
\hline \multirow[t]{2}{*}{$\begin{array}{l}\text { Chain conveyor } \\
\text { speed, } \mathbf{m} / \mathbf{m i n}\end{array}$} & \multirow[t]{2}{*}{$\begin{array}{c}\text { Spreader } \\
\text { speed, } \mathrm{m} / \mathrm{min}\end{array}$} & \multicolumn{3}{|c|}{$\begin{array}{c}\text { Application rate of manure (tones/ha) at selected } \\
\text { levels of forward speed }\end{array}$} \\
\hline & & $1.88 \mathrm{~km} / \mathrm{min}$ & $2.31 \mathrm{~km} / \mathrm{min}$ & $4.00 \mathrm{~km} / \mathrm{min}$ \\
\hline \multirow[t]{3}{*}{$2.26 \mathrm{~m} / \mathrm{min}$} & $25.12 \mathrm{~m} / \mathrm{min}$ & 16.16 & 10.39 & 6.93 \\
\hline & $37.68 \mathrm{~m} / \mathrm{min}$ & 16.40 & 9.94 & 7.22 \\
\hline & $47.10 \mathrm{~m} / \mathrm{min}$ & 16.92 & 10.08 & 7.06 \\
\hline \multirow[t]{3}{*}{$1.88 \mathrm{~m} / \mathrm{min}$} & $25.12 \mathrm{~m} / \mathrm{min}$ & 18.85 & 10.59 & 8.43 \\
\hline & $37.68 \mathrm{~m} / \mathrm{min}$ & 17.96 & 10.86 & 7.87 \\
\hline & $47.10 \mathrm{~m} / \mathrm{min}$ & 18.47 & 10.74 & 8.09 \\
\hline \multirow[t]{3}{*}{$1.51 \mathrm{~m} / \mathrm{min}$} & $25.12 \mathrm{~m} / \mathrm{min}$ & 20.11 & 12.22 & 9.22 \\
\hline & $37.68 \mathrm{~m} / \mathrm{min}$ & 20.41 & 12.62 & 8.87 \\
\hline & $47.10 \mathrm{~m} / \mathrm{min}$ & 20.25 & 12.02 & 9.46 \\
\hline
\end{tabular}

Table.2 Manure application rate and coefficient of variation at different manure delivery rate and speed of operation.

\begin{tabular}{|c|c|c|c|c|c|c|c|}
\hline \multirow{3}{*}{$\begin{array}{c}\text { Average } \\
\text { manure } \\
\text { delivery rate, } \\
\mathrm{kg} / \mathrm{s}\end{array}$} & \multirow{3}{*}{$\begin{array}{c}\text { Average } \\
\text { manure } \\
\text { application } \\
\text { swath, m }\end{array}$} & \multicolumn{6}{|c|}{$\begin{array}{c}\text { Manure application rate and coefficient of variation (CV) of } \\
\text { uniformity at different forward speed of tractor }\end{array}$} \\
\hline & & \multicolumn{2}{|c|}{$0.41 \mathrm{~m} / \mathrm{s}$} & \multicolumn{2}{|r|}{$0.69 \mathrm{~m} / \mathrm{s}$} & \multicolumn{2}{|r|}{$1.12 \mathrm{~m} / \mathrm{s}$} \\
\hline & & t/ha & $\mathrm{CV}, \%$ & t/ha & $C V, \% C D(a \times b)$ & t/ha & $C V, \% C D(b \times c)$ \\
\hline 0.46 & 2.0 & $5.82^{\mathrm{a}}$ & 7.45 & $3.48^{\mathrm{b}}$ & 9.7222 .9 & $2.05^{c}$ & 11.2017 .0 \\
\hline 1.05 & 2.0 & $12.62^{\mathrm{a}}$ & 7.68 & $7.55^{b}$ & 9.7715 .9 & $4.45^{c}$ & 11.367 .15 \\
\hline 2.06 & 2.0 & $25.75^{a}$ & 8.13 & $15.17^{b}$ & 10.4028 .15 & $9.09^{c}$ & 12.663 .32 \\
\hline 3.06 & 2.1 & $36.30^{a}$ & 8.88 & $20.96^{b}$ & 11.7329 .01 & $12.9^{c}$ & 13.212 .8 \\
\hline
\end{tabular}

Mean differences of $a \times b$ and $b \times c$ within the rows are significantly different at $p=0.05$ for paired " $t$ " test. Moisture content of farmyard manure: $28 \%(d b)$.

Fig.1 Hopper with centrifugal spreader disk

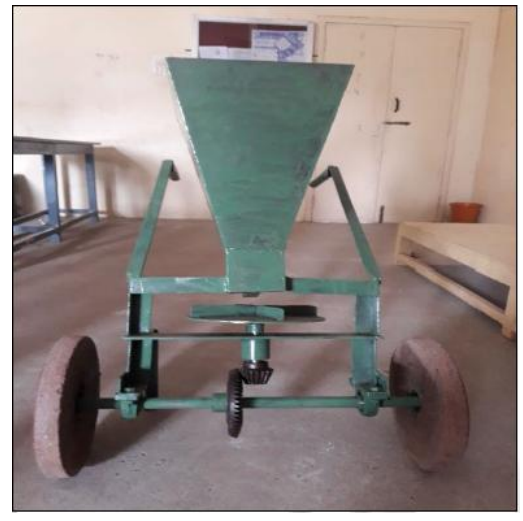


Int.J.Curr.Microbiol.App.Sci (2019) 8(9): 2530-2539

Fig.2 Spreader layout (Vignesh et al., 2017)

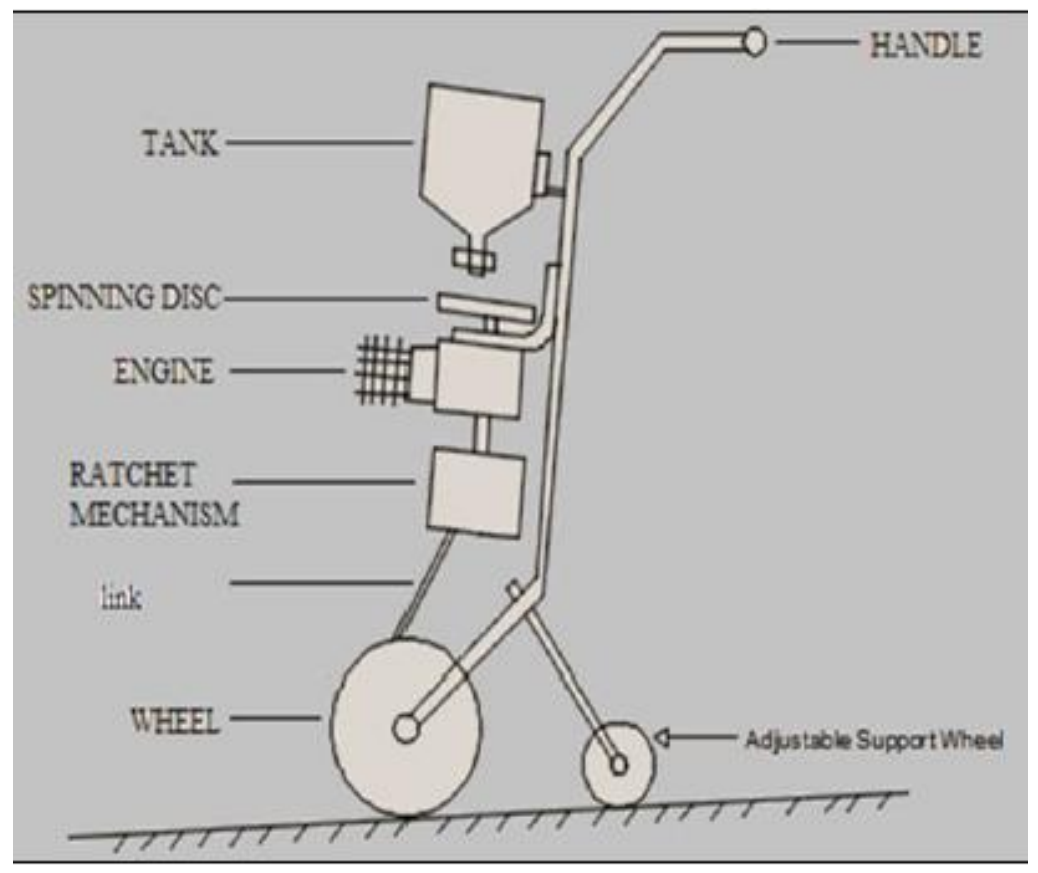

Fig. 3.a Conveyor

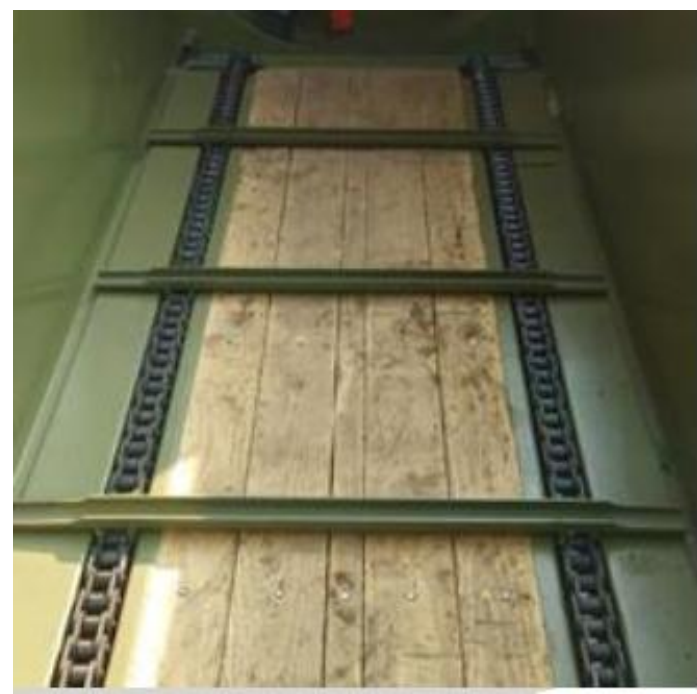

Fig. 3.b Centrifugal wheel

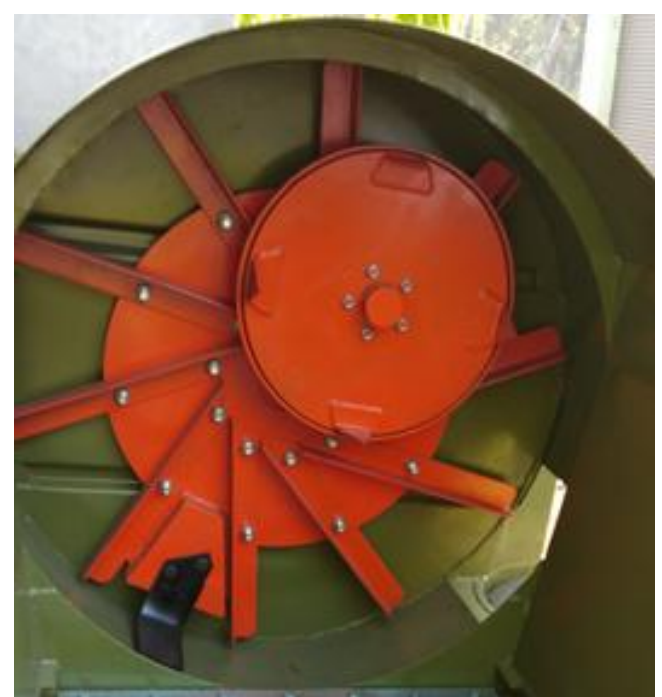


Fig.4 Chain conveyor

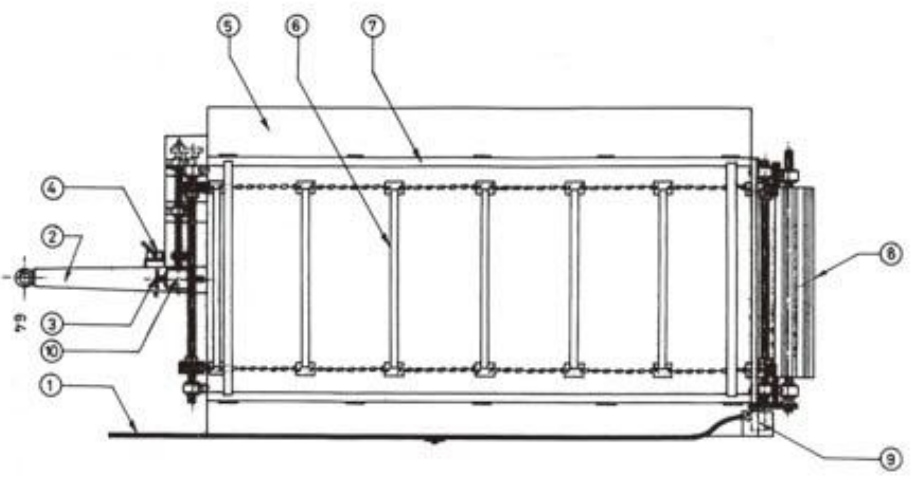

\begin{tabular}{|c|l|c|l|}
\hline 2 & HITCH FRAME & 7 & MANURE TUB \\
\hline 3 & PTO. DRIVE COUPLING & 8 & SPREADER \\
\hline 4 & PARKONG STAND & 9 & HYDRAULIC MOTOR \\
\hline 5 & TRACTOR TRAILOR & 10 & REDUCTION GEAA BOX \\
\hline
\end{tabular}

Fig.5 Spiral auger used for manure spreading

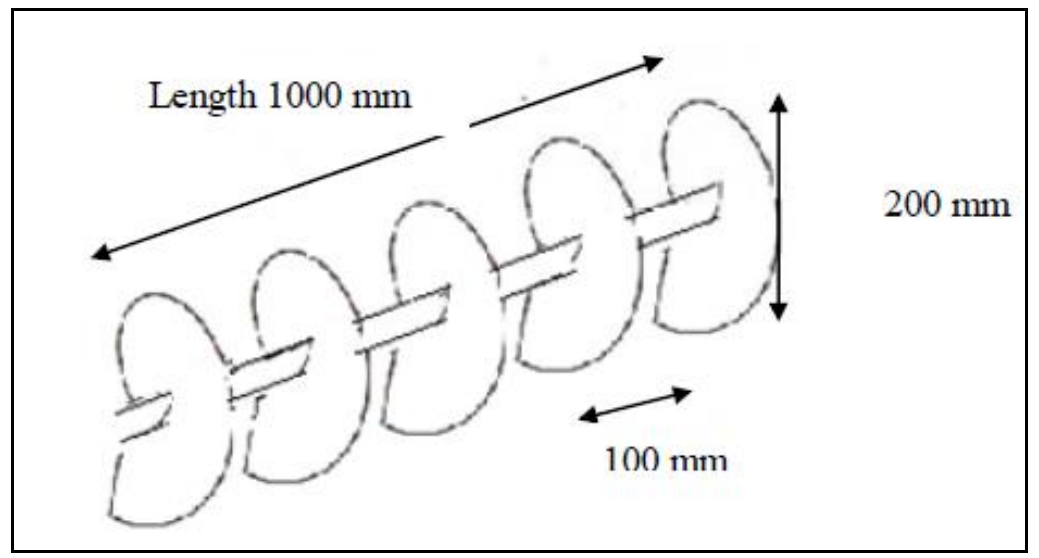

Fig.6 Tractor operated farmyard manure spreader with adjustable frame opening

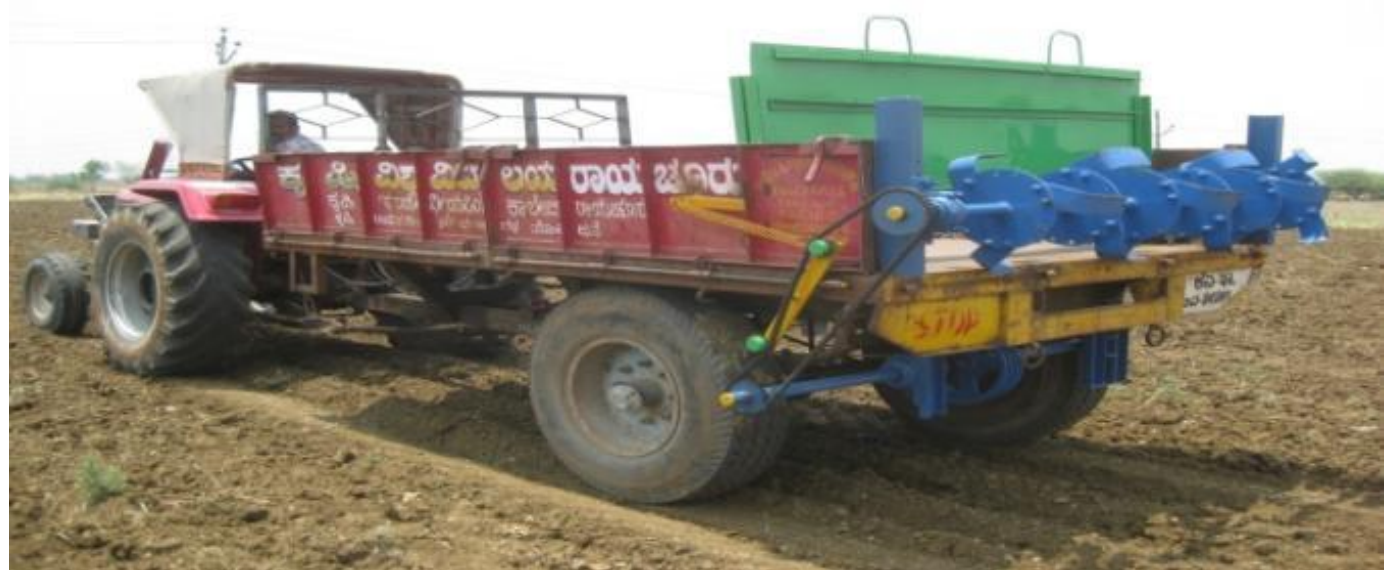


Fig.7 Effect of Engine Rpm and Forward Speed on Manure Application Rate and Field Capacity

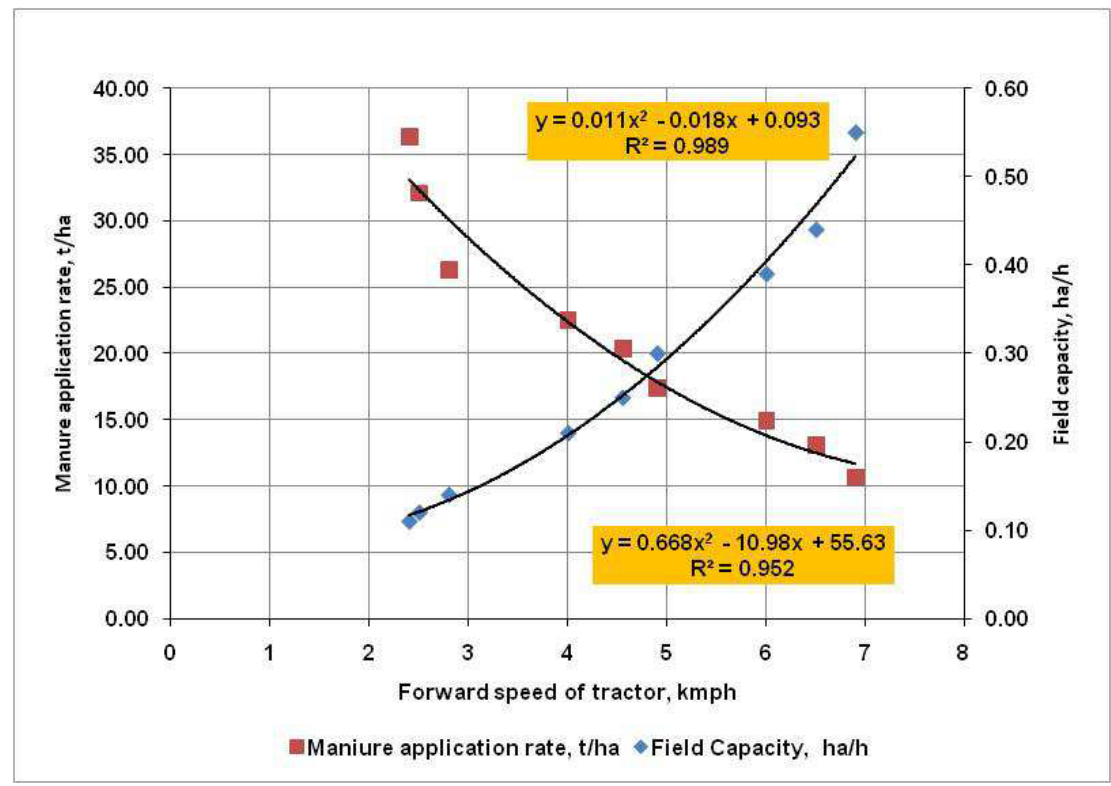

In the same way results of Sharabasy et al., (2007) shows that the increasing the gate opening area leads to increase the application rate $(\mathrm{kg} / \mathrm{h})$, but the increase in machine forward speed leads to decrease the application rate $(\mathrm{kg} / \mathrm{fed})$ due to the increase in machine field capacity. In another research of Batta et al., (2015) the effective field capacity of the manure spreader increased with increase in forward speed and engine rpm. As the forward speed of the tractor was increased engine rpm the effective length over which the manure was spreaded also increased. Thus it leads to increase in effective area over which the manure was applied resulting in decrease in manure application rate per unit area.

The effect of engine rpm and gear individually and in combination was significant on $(p<0.05)$ on manure application rate. As the engine rpm level and gear levels were increased the manure application rate Fig.7.

\section{Factors affecting uniformity in application}

Suthakar et al., (2008) measured the spread pattern for the all the treatments. Where they were plotted using values averaged over three replications with tray position in $\mathrm{X}$-axis and amount of manure collected in tray is in $\mathrm{Y}$ axis.

The application in tones per hectare decreased with increase in speed of the tractor and increase with decrease in the linear speed of the chain conveyor. In all the treatments spread pattern obtained was a flat top profile, which was acceptable form from the point of achieving uniform spreading.

It is very much evident that the forward speed and chain conveyor speeds had a significant effect on the uniformity of application. Similarly Sapkale et al., (2010) and Thakur et al., (2015) also recorded that the forward speed and conveyor speed had a significant effect on co-efficient of uniformity in manure application.

It was recorded by Hanna and Richard, 2008 that the varying spreader swath interval affects application rate and uniformity. In general, a narrower swath interval increases application uniformity, but increases overall application 
rate. Singh and Singh, 2013 have recorded that the increase in manure application rate will decrease the co efficient of variation, which in turn increase the coefficient of uniformity.

Jain and Lawrence, 2015 also have showed that the coefficient of uniformity of the manure spreader also varied with variation in manure delivery rate. The co-efficient of variation decreased from 23.42 per cent to 15.62 per cent with increase in manure delivery rate from $0.38 \mathrm{~kg}$ to $0.83 \mathrm{~kg} / \mathrm{s}$.

Very least work has been done on design of manure spreader. The existing tractor drawn Manure spreader is heavy and difficult to maintenance. The performance of this spreader on farm field gives effective spreading with low cost and reduction of time, while animal drawn spreader require separate cart which is used only for carrying manure. It require spiral auger which is complex to manufacturing. The animal drawn spreader is economically efficient but it consume more time as compared to tractor drawn spreader. Review also underlines the need of manure spreader which is easy to operate and design.

\section{References}

Batta, R., Narang, M. K. and Chandel, R. 2015. Field and economic studies of tractor operated manure Spreader with rear vertical rollers- a need based study for organic farming approach in indian agriculture. International Journal of Agricultural Science and Research. 5: 347-356.

Hanna, H. M. and Richard, T. L. 2008. Calibration and uniformity of solid manure. Agric. Envi. Ext. Publications. 13: 1-7.

Jain, A. K. and Lawrence, A. K. A. 2015. Performance Evaluation of Bullock Drawn Farm Yard Manure. International Research Journal of
Engineering and Technology. 2: 313316.

Jayamoorthy, M., Raj, A. S. A. P. and Jayabharath, P. 2018. Agriculture Manure Spreader for Natural Farming. International Journal for Scientific Research and Development. 6: 163615.

Kepner, R.A., Roybainer and Barger. E.L. 1978. Principles of farm machinery. Text book.

Krishanchandra. 2005. Organic manure. Unpublished thesis. M.sc. Univ. Agric. Sci. Dharwad.

Kunal, K. M., Saurabh, J. S., Mohit, L. S. and Priyanka, G. 2018. Design \& Fabrication of Cow-Dung Spreader. International Journal for Research in Engineering Application and Management. 8: 552-556.

Malgeryd, J. and Wetterberg, C., 1996. Physical properties of solid and liquid manures and their effects on the performance of spreading machines. J. Agric. Engg. Res. 64: 289-298.

Mehring, A. L., and G. A. Cumings. 1930. "Factors Affecting the Mechanical Application of Fertilizers to the Soil," U.S. Department of Agriculture, Technical Bulletin No. 182, Superintendent of Documents, U.S. Government Printing Office, Washington, D.C.

NaveenKumar, C., Prakash, K. V., Anantachar, M., Veerangouda, M. and Nagaraj. N. 2017. Performance Evaluation of Tractor Operated Farmyard Manure Spreader. Res. J. of Agric. Sci. 8: 816-820.

Patil, S. T. and Munde, P. A. 2017. Performance evaluation of an animal drawn manure spreader cum cart. Engineering and technology in India. 8: 80-92.

Reddy, M., Prakash, K. V., Veerangouda, M. and Yarnal, R. S. 2013. Development 
of animal operated farm yard manure applicator. Int. J. Agric. Engg. 6: 519523.

Sapkale, P. R., Mahalle, S. B. and Bastewad, T. B. 2010. Performance evaluation of tractor operated manure spreader. Int. J. Agric. Engg. 3: 167-170.

Sathyanarayana, V., Varaprasad, P. V., Murthy, V. R. K. and Boote, K. J. 2002. Influence of use of farmyard manure and inorganic fertilizers on yield and yield components of irrigated lowland rice. J. Plant Nutri. 25: 20812090.

Sharabasy, M. M. A., Ali, M. M. A. and Afify, M. K. 2007. Manufacturing and evaluation of a self-propelled machine for broadcasting seeds and granular fertilizers. J. Agric. Engg. 24: 752-774.

Shen, B., Satow, T. and Maeda, S. 2011. Evaluation of travel tracks of tractor drawn manure spreaders using RTKGPS. Engg. Agric. Envi. 4: 112-118.

Singh, R. C. and Singh, C. D. 2013. Development and performance testing of a tractor trailer cum farmyard manure spreader. Agric. Engg. Today. 37: 65-79.

Singh, R. C. and Singh, C. D. 2014. Design and development of an animal drawn farm yard manure spreader. African J. Agric. Res. 9: 3245-3250.

Suthakar, B., Kathirvel, K., Manian, R. and Manohar, J. D. 2008. Development and performance evaluation of manure spreading attachment to two wheel trailer. AMA. 39: 22-28.

Thakur, S., Chandel. And Narang, K. 2015. Evaluation of tractor operated manure spreader with rear vertical rollers. J. Agric. Res. 52: 54-58.

Vignesh, B., NavaneethaKrishnan, M. and Sethuraman, N. 2018. Design \& Fabrication of Automatic Fertilizer Spreader. Int. J. for Sci. Res. and Dev. 5: 1133-1135.

Yadav, G.D. and Pawar, M.S. 2015, Design and Development of Manure Spreader - A Review. Int. J. of Engg. Res. and Gen. Sci. 3: 262-265.

\section{How to cite this article:}

Naveen Kumar, C. and Kalyan Chakravarthi, N. L. 2019. Design, Development and Performance Evaluation of Manure Spreader- A Review. Int.J.Curr.Microbiol.App.Sci. 8(09): 2530-2539. doi: https://doi.org/10.20546/ijcmas.2019.809.293 